\title{
Erratum zu: Managementmodelle von Industrie- und Gewerbegebieten
}

\section{Abhängigkeit und Potential von gegebenen Strukturen}

\author{
Peter Bank $\cdot$ Martin Reinfeldt
}

Online publiziert: 9. Januar 2013

(C) Springer-Verlag Berlin Heidelberg 2013

Erratum zu: uwf (2012) 20:105-113

DOI 10.1007/s00550-012-0253-0

Die Reihenfolge der Autoren war falsch. Sie muss lauten:

Peter Bank · Martin Reinfeldt.

Der korrespondierende Autor ist Martin Reinfeldt und nicht Herr Bank.

Die Online-Version des Originalartikels ist erreichbar unter doi: 10.1007/s00550-012-0253-0

\section{Reinfeldt $(\bowtie)$}

Renforcement des Capacités de la Gestion durable des Zones

Industrielles (ReCapZI), Deutsche Gesellschaft für Internationale

Zusammenarbeit (GIZ) GmbH, Rez de chaussée,

14 Rue Nouvelle Dheli, Montplaisir,

1002 Tunis-Belvédère, Tunesien

E-Mail: martin.reinfeldt@giz.de

P. Bank

Ifanos Concept \& Planung, Vordere Cramergasse 11, Eingang E9,

2. Stock rechts, 90478 Nuernberg, Deutschland 